\title{
JUSTICIA INTERCOMUNAL EN LAS COMUNIDADES AIMARAS DEL SUR ANDINO (Segunda parte)
}

\section{Antonio Peña Jumpa}

\section{PROCEDIMIENTOS Y RACIONALIDAD EN LA RESOLUCIÓN DE CONFLICTOS}

EN EL PROCEDIMIENTO DE RESOLUCIÓN de los conflictos intercomunales, podemos apreciar la utilización de los mismos instrumentos de los procedimientos de resolución aplicados a los conflictos intracomunales en las comunidades de estudio ${ }^{67}$. En esta actuación destaca particularmente la presencia del honor familiar y del ser colectivo como dos principios fundamentales que promueven el procedimiento de resolución.

- El texto siguiente es la continuación de la primera parte del ensayo o artículo presentado en el número anterior de la revista. En la primera parte se desarrolló la introducción al tema, la descripción de los tipos de conflictos intercomunales y los órganos o autoridades que intervienen en su resolución. Esta segunda parte trata de los procedimientos y racionalidad en la resolución de los conflictos intercomunales, los acuerdos y decisiones finales tomados al respecto y el procedimiento de ejecución de éstos. Con ello completamos el "sistema de resolución de conflictos intercomunales o externos" de las comunidades aimaras de estudio, que a su vez se integra a lo que identificamos como "Poder Judicial comunal aimara".

${ }^{67}$ Ver al respecto Peña $(1998,2001)$. 


\section{ANTONIO PEÑA JUMPA}

Intentaremos siempre referirnos por separado a cada tipo de conflicto, buscando mostrar las diferencias que pueden identificar los conflictos intercomunales de carácter privado o familiar y a los de carácter colectivo o comunal, respectivamente.

\subsection{Procedimiento de resolución en los conflictos de interés particular o familiar}

La regla general para este tipos de conflictos intercomunales es que llegan, al final, a ser formalizados ante las autoridades político-comunales, contrariamente a los conflictos de naturaleza intracomunal, que tienden más bien a una no formalización. Se trate de conflicto de pareja, daños, incumplimiento del contrato de reproducción de ganado o de «engorde» o los propios conflictos de linderos de parcelas, son las autoridades políticas comunales, además de ser convocadas para su resolución, las que formalizan finalmente el acuerdo.

En los casos de "cría» o «engorde» de ganado es probable que la preeminencia de la intervención de las autoridades político-comunales se relativice, en tanto, como ya indicáramos, del carácter escaso de dichos conflictos, ya que, al suscitarse, resultan ser las propias partes las que se convocan para «arreglarlos». De no existir tal "arreglo", brota más bien de las mismas partes una insatisfacción permanente por un «nunca más hacer contrato con ese comunero». Es una especie de sanción privada que se aplicará para el futuro, sin necesidad de su registro formal, pudiendo adquirir más fuerza que el propio acuerdo formal, en tanto tal insatisfacción será extendida a sus familiares.

Sin embargo, interesa destacar en esta parte cómo llegan los comuneros a la solución del conflicto, importando sólo en parte si el acuerdo o decisión final se formaliza o no.

Igual que para los conflictos intracomunales de carácter familiar o privado, destaca el diálogo como principal instrumento de autocomposición. Se trata del diálogo en aimara entre los diferentes órganos informales (padres, padrinos, abuelos, familiar mayor o las propias partes intervinientes), quienes participan primero en el ámbito familiar de cada una de las partes, para luego acudir al contacto interfamiliar con la otra parte. Se busca llegar a un consenso o 
acuerdo en el seno de la parte familiar en pleito para luego buscar el mismo tipo de solución en la confrontación con la otra parte familiar. Es como una etapa de negociación en la que ambas partes pueden ceder parte de sus pretensiones.

Luego de que se haya llegado a un acuerdo con las familias en pleito, recién resultan convocadas las respectivas autoridades políticas comunales.

El diálogo en aimara también estará presente en esta participación de las respectivas autoridades comunales. Éstas harán llegar su opinión sobre las respectivas posiciones adoptadas, aunque pueden limitarse a acatar los acuerdos ya asumidos por las respectivas partes privadas. En tal sentido, la autoridad comunal se restringe a dar fe de lo acordado; como un gran fedatario, ésta va a ser testigo $y$ a su vez responsable de que tal acto formalizado se cumpla o se respete desde ambas partes.

En estas situaciones, para el arribo del acuerdo de las propias partes familiares, resulta indudable que éste sólo es posible a través del impulso del honor familiar. Cada comunero en litis, y sus respectivas familias nucleares, tiene entendido que está en juego su honor familiar frente a la vista no sólo de su comunidad de origen, sino también frente a la comunidad de la que es origen la otra parte. Sea cualquiera el tipo de conflicto, con mayor razón si adquiriera el carácter de colectivo, la idea del honor impulsará la efectividad del diálogo entre los órganos informales, el rápido "arreglo" y la posibilidad de su propio cumplimiento.

En los conflictos de pareja de jóvenes, por ejemplo, la búsqueda del diálogo entre los familiares de cada uno de los jóvenes convivientes o esposos se presenta como fundamental para preservar el honor de su propia parentela. Luego de agotada la posibilidad de conciliación de la pareja, queda definido como parte de su propio honor que la pareja se separe, que se concluya con su unión y se vuelva a la situación anterior, a pesar de haber podido procrear algún hijo ${ }^{68}$.

${ }^{68}$ Como se indicara en trabajos precedentes (Peña, 1998, 2001), el hijo producto de una relación de pareja que luego se frustrará puede llegar a ser protegido incluso por sus abuelos, quienes lo querrán como un futuro acompanante de sus faenas diarias. 
Para ello, como resulta lógico, ha habido un seguimiento del problema por los propios órganos informales de resolución. Con antelación, los padrinos (si la pareja es casada) o los padres sabían de los «maltratos», de las «riñas», de las incomprensiones. Dialogarán sucesivamente para mantener la unión de la joven pareja, buscarán enfrentar las causas del problema o conflicto «aconsejando» permanentemente a la pareja; al final, tendrán que resignarse a la separación inevitable. Luego de haber llegado a un acuerdo entre estos órganos informales, se recurrirá al apoyo de las autoridades políticas comunales para que registren dicho acuerdo.

El acto de formalización es un ritual particular. A una hora y fecha determinada, la parte "demandante" -que puede ser la de la mujer o el varón- concurre conjuntamente con sus familiares, en su caso con el padrino y con sus autoridades políticas comunales, ante la comunidad de la parte "demandada", la que a su vez esperará acompañada también de sus familiares y de sus autoridades. En la reunión, que se desarrolla en el local de la autoridad de recepción o su local comunal, las partes exponen la declaración de sus posiciones, que las autoridades ratifican:

"Tercero: Escuchado las manifestaciones del demandante la mas y falta de voluntad, ambas por no comprentirse y llevarse a una veda carinosa que nos presenta entre nosotros que convevimos y (que) además el demandado reconoce sus pleitos y problemas que hace a su convevienta y haciendo una vida imposible que siertamente existe la empresión de no llevarse (toda la vida),

"(...) ante la autoridad manifiesta(n) sus voluntades de separarse definitivamente ellos(;) no queda recurso que ambos pone fin de ese momento. (Las) autoridades (atienden) a los exposiciones de ambas partes después de haber buscado la conceliación por distintas formas y medios de no haber consiguido (...)" 69 .

69 Titihue: "Acta de separación entre las personas NMM (y) ML de la comunidad de Huancho", en Libro de antecedentes, acta de fecha 11-4-95. 
Puede apreciarse cómo las partes exponen sus posiciones, reconociendo propiamente sus limitaciones, vinculadas a las causas que producen el conflicto de separación y destacando previamente el ejercicio de su voluntad por conseguir la reconciliación de la pareja, intento que habría estado bajo gestión directa de los familiares y sólo con el respaldo de las indicadas autoridades. Ello es formalizado, destacando como un acto central el reconocimiento de los errores de las partes, en los conflictos de pareja para luego llegar a un acuerdo.

De otro lado, en los conflictos de reproducción o «engorde» de ganado, el procedimiento de resolución también se ve identificado por el diálogo en aimara entre los comuneros que son parte, influidos por su respectivo honor familiar. Aunque, como adelantamos, no es común que se recurra a la formalización del acuerdo o decisión de las partes una vez agotado su procedimiento de resolución.

La parte que se siente afectada por el incumplimiento del contrato no dejará esperar su intervención para "aclarar» la situación. Ambas partes, al momento de la distribución de la "cría" del ganado o en el momento inmediatamente posterior a la venta del ganado "engordado", si no encuentran satisfechas sus pretensiones, se pondrán a discutir los términos de lo que creían acordado verbalmente. Ello puede producir que en ese momento brote el «mejor arreglo" y quede allí el conflicto; pero también puede ocurrir que no se produzca ningún acuerdo y quede insatisfecha una de las partes; entonces, más que recurrir a sus respectivas autoridades políticas comunales, recurrirán a la sanción privada económica: «Nunca más hará contrato con tal comunero". Se considerará a este comunero como una persona disminuida en su honor familiar, no conveniente para efectuar este tipo de tratos, lo que se extenderá entre los familiares del insatisfecho y los familiares de la otra parte.

Lo que destaca de estos procedimientos de resolución de conflictos contractuales es que el honor familiar siempre conduce a acelerar el acuerdo. La confianza y honestidad que guió la celebración del contrato es difícil que desaparezca al suscitarse el conflicto sobre su cumplimiento. La búsqueda del "arreglo armonioso" mediante la "comprensión mutua" estará presente en la concepción de los comuneros en pleito. 
De otra parte, el procedimiento de resolución de los conflictos de linderos donde interviene un "yerno" de la comunidad es asumido como si se tratara de naturaleza intracomunal. En estos casos, al ser los propios órganos de la comunidad en que se desarrolla el conflicto los competentes para resolverlo, recurrirán al mismo procedimiento que utilizan al interior de su comunidad.

Como en los conflictos intracomunales, las propias partes son, en principio, las que buscan solucionar el conflicto: el "yerno" como titular de la parcela de su conviviente o esposa y el comunero vecino como titular de su propia parcela. Recurrirán, por tanto, a los propios instrumentos de conciliación que en ellos existen, destacando nuevamente el diálogo en aimara impulsado por el honor familiar. Si el conflicto no se resuelve, pasarán a los otros órganos informales de resolución (familiares mayores o ancianos) o directamente a las autoridades de la comunidad donde se encuentran las parcelas cuyos límites están en discusión. En esta última situación, las autoridades podrán intervenir como conciliadores o mediadores, dependiendo de la disposición de las partes intervinientes y, en todo caso, como árbitros que impondrán una solución.

Recordemos que la intervención de las partes puede conllevar a una solución rápida sin necesidad del registro del acuerdo. Tal situación ocurre ante la poca relevancia, en opinión de los comuneros parte, sobre la parte en discusión de los límites de su parcela. Pero puede ocurrir que rápidamente también lleguen a un acuerdo mediante concesiones recíprocas: sacrifican mutuamente parte de las parcela que creían suya.

En el caso de la intervención de las autoridades políticas comunales, el legitimado a comparecer es la esposa o conviviente del "yerno" no residente, quien es originaria de la comunidad. Ella, acompañada de sus propios familiares de la comunidad, se sentirá con el mejor derecho a reclamar lo que considera su pretensión. Los familiares mayores y los ancianos respaldarán la búsqueda de solución promovida por las autoridades, mientras que el «yerno» no residente actuará, en tal caso, como un comunero sumiso ante lo que se disponga entre los órganos intervinientes. El espíritu de conciliación siempre estará presente en éste, su intención de diálogo, su comprensión del problema y, más aún, en el entendido de que resulta ser un "extraño" propiamente para la comunidad. 
JUSTICIA INTERCOMUNAL EN LAS COMUNIDADES AIMARAS

3.2 Procedimiento de resolución en los conflictos de interés colectivo o comunal

En los conflictos colectivos o comunales de carácter intercomunal, el procedimiento de resolución está sujeto siempre a la iniciativa de las autoridades comunales, que tratan de conseguir con celeridad una decisión o acuerdo que ponga fin al conflicto. Al tratarse del interés colectivo de la comunidad afectada, sus autoridades, junto con la asamblea, promoverán los mecanismos más adecuados para arribar a la mejor solución.

Como en los conflictos intracomunales, el conjunto de los comuneros entiende que en la presencia de estos conflictos colectivos o comunales se encuentra un gran obstáculo para su orden comunal o para lo que ellos mismos denominan su «progreso comunalı ${ }^{70}$. Las comunidades parte del conflicto reivindican de esta forma su propio principio del ser colectivo.

La tranquilidad o la armonía comunal, el estado de normalidad en el cual el conjunto de comuneros pueda seguir desarrollando sus actividades económicas, sociales y culturales motiva una celeridad por la solución del conflicto que responde a una identidad más general de las comunidades en pleito: el hecho de ser aimaras. Ello motiva, con bastante énfasis, que la comunidad afectada o las comunidades en pleito piensen que hay que resolver el conflicto por ellas mismas. Con la presencia de sus propias autoridades y alentados por el «mejor arreglo» llegan a conciliar como dos pequeñas naciones que estuvieron en disputa.

En el conflicto de robo de ganado, por ejemplo, si llegaran a identificar al autor, las autoridades y miembros de ambas comunidades -de aquella donde se produjo el robo y de aquella en que es de origen el supuesto ladrón- no dudarán en sancionar al irresponsable e incluso entregarlo a las autoridades de la ciudad, con tal de superar el conflicto.

Pero más que este resultado final del procedimiento de resolución del caso, lo interesante a resaltar son los momentos iniciales de búsqueda del ganado, lo que constituye la mayor satisfacción

${ }^{70}$ Calahuyo, Titihue, Tiquirini-Totería, Huancané, 1988, 1992, 1999, 2000. 
para el afectado. Dentro de esta etapa inicial, debemos indicar que, ocurrido el robo, toda la comunidad se reúne, las autoridades ya están listas para intervenir, pero los propios comuneros verán conveniente sumar otros más que hagan en conjunto una comisión que concurra en la búsqueda de las huellas del ganado y la captura de los ladrones. En esta comisión estará presente el propio afectado del robo y las autoridades.

Con el grupo así conformado, que puede hacer un total de ocho a diez miembros, se hace un seguimiento de las huellas del ganado sustraído. Con palos, hachas, látigos y otros instrumentos propios de su actividad laboral, los comuneros se desplazan de una a otra comunidad hacía donde se pudo haber dirigido el ladrón. En este desplazamiento se produce el contacto con las autoridades de las comunidades vecinas, a las que se hace presente la preocupación del robo para que sea de conocimiento de toda la microrregión, como hemos indicado.

Este procedimiento de búsqueda, si es rápido, es efectivo. En Titihue, la pérdida de tres cabezas de ganado de un comunero, en julio de 1992, fue superada gracias a la rapidez de su procedimiento de resolución. Los comuneros lograron dar con las huellas, no había habido lluvia de por medio y entonces lograron seguir con calma dichas huellas, cruzando cerros hasta llegar a las cuevas cercanas de una comunidad conflictiva, en las que encontraron abandonado el ganado.

Una muestra de la actuación de los comuneros en la búsqueda del ganado puede apreciarse en el siguiente caso, en que la comunidad de Jasana Chico de Samán sufrió el robo de dos toros y un burro. En la actuación inmediata, los comuneros encuentran a un supuesto "cómplice" en territorio de Titihue, lo detienen y lo llevan a las autoridades de esta comunidad; luego aparecerá una tercera comunidad, de la que es originario el detenido, la que reivindicará su inocencia:

"Primero: El presidente de la comunidad (de Titihue) don JMR dio la bienvenida a las autoridades de Jasana Chico de Samán y a los comuneros; las autoridades de Jasana Chico, especialmente el teniente gobernador manifesto deciendo 


\section{JUSTICIA INTERCOMUNAL EN LAS COMUNIDADES AIMARAS}

premeramente que (él) agradece por la recepción y luego manifiesta que el culpable es la persona quien ha recibido el ganado o sea dos toros y un burro, nosotros bien claro decimos que él es otro de los cómplices de muchas pérdidas, por tal razón pedimos que se nos haga arreglo sobre esta pérdida, también muchas de sus autoridades manifiestan igual (...). Luego participó el Teniente Gobernador de Titihue, deciendo quien aisido el interesado manifestó que un vecino lo avisó deciendo que a sus ganados se los están llevando, recien se dio cuenta (...).

Despues llegaron las autoridades familiares de don CCI (supuesto cómplice) y comuneros de Caminacuya, inmediatamente pedió el esclarecimiento de cómo fue detenido Don $\mathrm{CCI}$ (;) sobre esto el Teniente de Jasana Chico manifestó que lo detuvieron en el camino en la comunidad de Titihue y lo llevaron ante el Presidente de Titihue, sin hacer ningún tipo de maltratos(;) el detenido manifiesta que el venía de Juliaca después de despachar a su hermano Remigio; el detenido estaba descansando comiendo su pan (...).

Despues de mucha discusión la parte interesada comprende que dicha persona detenida que es inocente sobre la perdida de dos ganados y un burro de Jasana Chico del destrito de Saman"71.

La cita describe el conjunto de actividades que involucra una reacción inmediata de parte de las autoridades de la comunidad de Jasana Chico (Samán), situada a varios kilómetros de Titihue, para seguir las huellas del ganado y encontrar al supuesto "cómplice". Con el apoyo de las autoridades de Titihue y la presencia de las autoridades de la comunidad de Caminacuya (a la que pertenece el detenido), se consigue determinar la responsabilidad del supuesto "cómplice". Parece ser que hubo un error en la captura del indicado comunero, pero la acción realizada por la comunidad de Jasana Chico sirvió para encontrar, al día siguiente, los dos toros y el burro

71 Titihue: "Robo de ganado en Jasana Chico (Samán) con detención de supuesto cómplice", en Libro de antecedentes, acta de fecha 15-1-98. 


\section{ANTONIO PEÑA JUMPA}

sustraídos, que fueron dejados aparentemente al hijo de un comunero de Titihue ${ }^{72}$.

Sin embargo, en esta labor de búsqueda también pueden ocurrir limitaciones. La cercanía a una carretera puede significar el desplazamiento rápido, mediante vehículo, de los ladrones. Los factores meteorológicos, como una granizada que arrase o una fuerte lluvia en la madrugada, antes de iniciar la búsqueda, pueden dificultar el seguimiento de las huellas. Sin embargo, los comuneros también pueden entretejer estrategias frente a esos factores. Hay expertos comuneros que pueden seguir las huellas del ganado a pesar de la lluvia o granizada ocurrida, como también, cuando ocurre el robo en un vehículo, los comuneros saben dirigirse a los k'atos o ferias de los alrededores y de las ciudades vecinas para, con apoyo de otros comuneros testigos de otras comunidades, identificar a su ganado y a los ladrones. En último de los casos, pueden recurrir al pago a la tierra a través del yatiri de su confianza, con el fin de "detener" a los ladrones en su huida"3.

Debe destacarse el reproche colectivo de los comuneros de la microrregión por esos hechos. Nadie acepta que otro comunero $\mathrm{u}$ otra persona se apodere o apropie de un ganado que no crió o adquirió, a pesar que para ambos dicho ganado puede se un medio de subsistencia (tanto para quien lo cría y quien lo sustrae). Por ello, la solidaridad de los distintos comuneros, más allá de la actuación de las propias autoridades, no se deja esperar. Todos participan de una u otra manera en la búsqueda de solución al problema. Incluso, si no se consigue una respuesta rápida, se recurre a la Liga Agraria

72 La discusión sobre la aparición de los dos toros y el burro "extraviados" aparece registrada en el acta siguiente del Libro de antecedentes de Titihue. En esta acta también se hace entrega de los animales a las autoridades de Jasana Chico (Titihue: "Manifestación de 'honorabilidad e inocencia' de supuesto inculpado de robo de ganado en Jasana Chico - Samán y entrega de ganado encontrado", en Libro de antecedentes, acta de fecha 16-1-98).

73 Entrevista con Benito Gutiérrez Ccama, dirigente de la Liga Agraria "24 de Junio" de Huancané (Huancané, marzo de 1992, octubre de 1999, agosto del 2000). Particularmente en esta última entrevista, Benito Gutiérrez nos refirió la capacidad del yatiri como persona con poderes extraordinarios capaz de realizar actos de control de los ladrones a través del contacto con la "madre tierra". 
de los presidentes de comunidad y a la asamblea de tenientes para compartir la preocupación y cruzar información ${ }^{74}$.

Téngase presente también que estos robos de ganado no son casos comunes en Huancané. Por ello, los comuneros no han requerido de otro tipo de estrategias para superar tal malestar. La búsqueda mediante comisiones y la intervención de sus propias autoridades han sido suficientes para afrontar el problema, quedando sólo en referencias la conformación de rondas para una mayor eficacia. Sólo en el caso de que una banda de ladrones esté rondando la zona y afectando a varias comunidades, la organización para enfrentar tal problema no se dejará esperar ${ }^{75}$.

De otra parte, los conflictos de colindancia entre dos comunidades vecinas también tienen un procedimiento de resolución particular. En estos casos es posible que hablemos de los procedimientos de resolución más complejos, en tanto puede estar en discusión la integridad del territorio comunal. Tal como lo pudieron sintetizar dos dirigentes de la comunidad de Tiquirini-Totería, se trata de un procedimiento de resolución en el que destaca la participación del conjunto de comuneros con la "habilidad" de sus autoridades comunales $^{76}$.

En el desarrollo de los procedimientos de resolución cabe distinguir la actuación de las autoridades y su correspondiente asamblea en dos tipos de conflictos de colindancia: cuando se trata de la discusión sobre los cerros o pastizales de la comunidad que, al estar normalmente sin una vigilancia estricta, resultan motivo principal del inicio del conflicto de parte de la comunidad colindante; y cuando se trata de la discusión de parcelas de terrenos fronterizos, en las

${ }^{74}$ Entrevista con Benito Gutiérrez, Ibid.

75 Sólo a manera de referencia, podemos citar el caso ocurrido el año 1985 en la parte cercana de Tiquirini-Totería, en que un grupo de ladrones tenía atemorizadas a las comunidades del lugar. Se perdían los animales, las ropas y los instrumentos de trabajo sin llegar a determinar a los culpables. Entonces, las comunidades afectadas se organizaron por lugares y turnos nocturnos para dar con los ladrones. A los dos días lograron detectar a dos de ellos, y posteriormente al resto. Les dieron una fuerte paliza y los entregaron a las autoridades de la ciudad (Tiqurini-Totería, marzo de 1992).

76 Tiquirini-Totería, marzo de 1992. 
que más allá del interés y la voluntad de las familias identificadas como titulares o propietarias surge el interés de la organización comunal.

Tratándose de la afectación de los cerros de la comunidad, destaca la preocupación e intervención inicial de los comuneros y las autoridades de ambas comunidades. Cualquier comunero que vio a otro pastando con sus ovinos o su ganado en el monte que considera dentro de los "hitos» de su comunidad se siente en la obligación de poner en conocimiento de tales hechos a sus autoridades. Inclusive, puede tratarse de la intromisión de un niño pastor, a quien inicialmente llamen la atención, pero del que saben que hay un responsable mayor, que es el padre o familiar de este niño. No basta un solo acto de supuesta usurpación para que se suscite el conflicto, sino que tiene que tratarse de actos reiterativos o una relevante permanencia en la posesión sobre el terreno considerado "ajeno" por la parte reclamante.

Al tomar las autoridades conocimiento de los hechos -deduciendo la vocación de permanencia de la supuesta comunidad usurpadora o de los comuneros de ésta-, o al presenciar las mismas autoridades las supuestas transgresiones, toman la iniciativa de aclarar ante la otra comunidad los límites de sus respectivas comunidades. Pudo haber mediado en este intermedio una reunión ordinaria de parte de su asamblea comunal, como también, dada la gravedad de la usurpación, pudo haberse convocado de manera extraordinaria a la asamblea comunal para ir recogiendo una posición colectiva a sostener con la comunidad rival.

Posteriormente, las autoridades se reúnen con sus respectivos planos de la comunidad para fundamentar las supuestas usurpaciones. El diálogo y discusión se centran en la identificación de los «hitos» que fueron ubicados cada cierta distancia y que fueron colocados por ambas comunidades para acreditar los límites respectivos de sus territorios. Ciertamente, si el problema responde sólo a la "mala» actitud de un comunero, quien es el único que produce el traspaso de los límites, la comunidad a la que pertenece dicho comunero se someterá ante el reclamo de la comunidad afectada, comprometiéndose a sancionar internamente al comunero usurpador. El problema mayor es cuando ambas comunidades ale- 
JUSTICIA INTERCOMUNAL EN LAS COMUNIDADES AIMARAS

gan que determinado sector o franja les corresponde $y$, en consecuencia, sus comuneros libremente pueden pastar sobre dichos terrenos.

Ante la negativa de otorgar aclaraciones y la continuidad en el uso o posesión simultánea por ambas comunidades del terreno o franja en discusión, se agudiza el conflicto. En este momento se suceden permanentemente las asambleas para tratar el problema y encontrarle una solución. Si una de las partes o ambas minimizan su participación en estas asambleas continuas, el conflicto se va agudizando en el colectivo, hasta que llega un momento de explosión: se producen enfrentamientos verbales en las fiestas o k'atos frecuentes en los que se encuentran los comuneros.

Una vez que los colectivos de ambas comunidades han llegado al intercambio de palabras, el hecho llega a las comunidades vecinas e inclusive a sus respectivos gremios de la ciudad. Entonces el conjunto de familias de cada comunidad comienza a estar dispuesto a buscar una solución a su problema. El ser colectivo de ambas comunidades, influido por el qué dirán, incentiva la búsqueda de un nuevo acercamiento entre los órganos de resolución.

Son las autoridades comunales las primeras en insistir en la búsqueda de una solución. Presidente y teniente gobernador, acompañados de los directivos comunales, visitan a sus contrarios llevando la posición que corresponde a su comunidad o que ésta hubo acordado en la asamblea anterior. La conversación de parte de estas autoridades comunales, así como las opiniones que se hicieran presentes, serán explicadas, a su vez, en sus respectivas asambleas comunales. Éstas pueden abrir intentos de solución: se ratifican en la posesión de sus supuestos terrenos, pero ceden en otros aspectos, como puede ser el intercambio o "devolución" de determinado producto sembrado en el terreno en discusión o del ganado capturado en el mismo. Finalmente, pueden ceder hasta en la fragmentación o parcelación de parte de la franja o el terreno en discusión.

Con la opinión de sus respectivas asambleas comunales, las autoridades nuevamente son convocadas para cruzarse los correspondientes informes de sus comunidades. El ser colectivo, como expresión del conjunto de comuneros, nuevamente induce a las comunidades en conflicto a la búsqueda de solución. 
La opinión revisada de la asamblea comunal nuevamente será sometida a la otra parte a través de sus autoridades. En estos momentos ya pueden ir manifestándose intentos de solución, acuerdos coincidentes que harán ceder definitivamente la "terquedad" de ambas. Si las respectivas asambleas comunales aceptan, el conflicto termina allí: se produce el acuerdo final que se registrará en los libros de actas principales de cada comunidad. En caso contrario, la negociación continuará de la forma indicada o esperando, en todo caso, la aparición de un agente externo que haga ceder definitivamente a las partes ${ }^{77}$.

Como puede apreciarse, se trata de un complejo procedimiento de resolución de un conflicto bastante complejo que tiene como bien objeto de discusión el recurso que consideran fundamental los comuneros: la tierra. Si bien, como hemos indicado, actualmente los comuneros no recurren a enfrentamientos físicos con muertes subsecuentes, tal alternativa no puede descartarse por el nivel de importancia que le otorgan al recurso en discusión. Sin embargo, la voluntad autocompositiva de dichas comunidades fomenta en la fecha una negociación intercomunal que conlleva la búsqueda de solución a dichos conflictos en armonía.

En Calahuyo existe el antecedente de un conflicto de límites de territorios con las comunidades de Pampa Amaru y Antacahua. En este caso, el elemento de consenso fue la construcción de un colegio de educación secundaria. Después de mucho batallar en las negociaciones y de manifestarse el malestar de los comuneros vecinos, acordaron donar el terreno en discusión para la construcción de un colegio. En la cita siguiente podremos apreciar el consenso de parte de los comuneros de Calahuyo y Antacahua que puso fin al referido conflicto, figurando, para tal caso, ambas comunidades como donantes ante el Ministerio de Educación:

77 La presencia de las autoridades gremiales de la Liga Agraria "24 de Junio" de Huancané y la autoridad o el funcionario de un ministerio relacionado con las actividades de dichas comunidades pueden constituir estos agentes externos. 
"(...) acto seguido las autoridades y padres de familia de la comunidad de Calahuyo mostraron el perímetro de tres Hectareas de terreno que quieren donar a favor del ministerio para que se edifique el nuevo local de Instrucción Secundaria(;) constatado esto el director del (N)ucleo (escolar) ${ }^{78}$ les felicitó a todos los comuneros de Calahuyo, y a continuación pasaron a ver el terreno que también quiere donar a favor del Ministerio de Educación los comuneros de Antacahua Chacapampa para lo que todos los asistentes a la reunión nos trasladamos todos(;) llegando al sitio de igual manera el Director del $(\mathrm{N})$ ucleo les felicitó a los dueños de terreno a nombre de la comunidad de Antacahua-Chacapampa"79.

En el caso de conflictos de linderos de parcelas particulares de diferentes comunidades, el procedimiento de resolución es semejante. Aunque se debe resaltar la participación de los comuneros mayores o ancianos de la respectivas comunidades, quienes pudieran conocer con mayor precisión los límites de las parcelas que alguna vez se transfirieron a los comuneros del pleito. Se suma también, como elemento principal, la vehemencia o preocupación particular de los respectivos titulares de las parcelas.

Sólo para citar un caso, cabe referir la experiencia de algunas familias de comuneros de Calahuyo, titulares de parcelas vecinas a otras de la comunidad de Pampa Amaru, que tuvieron su confrontación con familias titulares de éstas. Parte de las parcelas de los comuneros de Pampa Amaru se encontraban dentro del territorio alegado por Calahuyo, e igualmente parte de las parcelas de los comuneros de Calahuyo se encontraban dentro del territorio alegado por Pampa Amaru. En esta situación, luego de prolongados diálogos entre autoridades, largos sometimientos a sus respectivos co-

${ }^{78}$ El Núcleo Escolar era una instancia educativa dependiente del Ministerio de Educación y ubicada en los distritos de las provincias del Perú. Luego la misma oficina administrativa pasó a recibir el nombre de Unidad de Servicios Educativos (USE).

79 Calahuyo: "Acta de reunión de autoridades del ámbito nuclear de Accoccollo (en el que se identifican terrenos que serán donados para poner fin a conflicto de colindancias), en Libro de actas I, acta de fecha 10-3-77. 
lectivos, se arribo al acuerdo de intercambiar las parcelas: los comuneros de Pampa Amaru se beneficiarían con las parcelas de los comuneros de Calahuyo, renunciando a las suyas en esta comunidad, y recíprocamente de parte de Calahuyo ${ }^{80}$.

Para estos casos de disputas territoriales, resulta interesante destacar, entre las comunidades vecinas, la aplicación de ciertas actitudes y reglas del Derecho Internacional Público. A manera de dos pequeños Estados, o mejor dicho, Estado-naciones, los comuneros interrelacionan a sus autoridades comunales como cancilleres y a su asamblea comunal como la fuente decisoria para llegar al acuerdo. En esta interrelación, las otras comunidades vecinas también comienzan a preocuparse por el «lío» y asumirán similar actitud. Intercambiarán a sus "cancilleres», se reunirán más de una vez, asistirán los "cancilleres» de las comunidades vecinas, hasta que se llegue a un acuerdo que, finalmente, quedará registrado en actas. La Liga Agraria de Huancané también puede intervenir, a manera de la gran organización de "naciones", haciendo llegar la opinión más valiosa y forzando siempre a que lleguen a un «mejor arreglo», antes de complicarlo con la fuerza o con los juicios interminables ante las «autoridades de la ciudad».

De otro lado, en cuanto a los conflictos derivados del incumplimiento de las obligaciones comunales del "yerno" o de las riñas en las que éste es parte frente a otros intereses familiares de la comunidad, el procedimiento de resolución que le corresponde es el mismo aplicable a los conflictos intracomunales de carácter colectivo. Los órganos de resolución comunal actúan con el propósito de someter y conducir al "yerno" dentro de los acuerdos y el orden comunal de la comunidad.

Así, en el caso del incumplimiento de obligaciones comunales, las autoridades requieren al "yerno" y en todo caso someten su incumplimiento ante el conjunto de comuneros. En ésta, nuevamente se recuerdan las "malas experiencias" tenidas con los "yernos", se les llama la atención y se procede a imponer sanción o a exigir el pago de la multa establecida por incumplimiento de las obligaciones comunales.

${ }^{80}$ Calahuyo, entrevistas a diferentes comuneros, marzo de 1988. 
Este procedimiento, en realidad, se desarrolla contra la esposa o conviviente del "yerno", quien es originaria de la comunidad en la que se ha suscitado el conflicto y a quien se la reconoce como titular de la parcela heredada de sus padres. Sin embargo, la extensión de la representación, dado el conjunto de relaciones patrilineales en las comunidades de estudio, también recae en el "yerno", figurando éste normalmente como el "irresponsable" requerido por los órganos de resolución de conflictos de la comunidad. En suma, se trata de una representación procesal de índole familiar también, y lo importante en la concepción de ésta es que ambos, "yerno" y esposa o conviviente, se obliguen a cumplir con los acuerdos que semanal o periódicamente fije la asamblea comunal o el sector respectivo, si es que quieren conservar sus parcelas.

En los casos de riñas entre familias de comuneros en las que una de las partes es "yerno" de la comunidad, la actuación de las autoridades y la asamblea comunal contra el "yerno" y su familia es de sometimiento total. En Calahuyo y Titihue, la experiencia de haber convivido con "yernos" conflictivos, "pleitistas" o "abusivos" ha hecho que, frente a tales conflictos, la reacción de las autoridades y asamblea sea más bien enérgica en su procedimiento de resolución. Una vez recibida la "demanda" o la "denuncia" del conflicto en el que ha participado el "yerno", hay una cierta presunción de su responsabilidad, debido a los indicados antecedentes. Si se encuentran indicios o pruebas que comprometen al "yerno", la reacción será mayor, exigiendo de éste la reparación inmediata de los daños y el cumplimiento de las sanciones correspondientes. En casos extremos, la misma comunidad recurre a la memoria de acuerdos anteriores, en los que se ratifican las amenazas de expulsión de los indicados "yernos". Por ejemplo, en el procedimiento de resolución de uno de los casos de "riñas con lesiones" con participación de un "yerno" en Titihue, luego del acuerdo sobre el conflicto en sí, se destaca:

“(...) que todo(s) los comuneros se manifiestan que se respete la acta anterior del año 85 que a los Yernos está noteficados para que no se consienta en la comunidad por razones de los 
errores que comiten. (A)simismo al final los despiden y notifican para que se retiren de esta comunidad. (E)n lo posterior puede haber muchos problemas y se dio 15 dias..." 81 .

Puede apreciarse que el procedimiento de resolución frente al conflicto en que es parte el "yerno" tiene una carga subjetiva adicional al que corresponde a los conflictos comunales regulares de la misma comunidad. Ello se encuentra fundado en la presencia y recuerdo de los antecedentes no agradables que los comuneros guardan de los "yernos". Pero, más aún, podemos encontrar su fundamento en el interés colectivo histórico -de parte de los comuneros- de proteger su territorio y orden comunal frente a "extraños" que pueden traer "desorden" o la pérdida de sus tierras. Ello nuevamente se ve garantizado por el carácter patrilineal en la sucesión preponderante de sus parcelas o el ejercicio de los cargos principales de la comunidad.

\section{LOS ACUERDOS O DECISIONES FINALES}

Como ocurre en los conflictos intracomunales en las comunidades de estudio (Peña, 1998, 2001), también se presentan los «arreglos»y las «sanciones» como dos instrumentos o instituciones que manifiestan la decisión final en los conflictos intercomunales. Por lo general, tanto "arreglos" como "sanciones» responden a la misma lógica de los conflictos que hemos calificado como familiares o comunales, pero con algunas diferencias.

Notaremos, de manera particular, cómo el «arreglo» puede aparecer como el acuerdo final frente a los conflictos intercomunales de interés colectivo más complejos que hemos presentado: el que coresponde a los linderos intercomunales. Como también podríamos notar cómo la «sanción» puede aparecer sin muchas limitaciones en determinados conflictos de carácter familiar: cuando se trata de los incumplimientos de los contratos de "cría» o «engorde» de ganado, por ejemplo.

81 Titihue: "Acta de comparencia (por riñas y lesiones propiciadas por 'yernos' de la comunidad)", en Libro de antecedentes, acta de fecha de noviembre de 1997. 
Procuraremos explicar la aplicación de estas dos instituciones de manera separada, incluyendo en ella los propios tipos de conflictos que hemos venido desarrollando desde acápites anteriores.

\subsection{Los «arreglos» aplicados en los conflictos intercomunales}

Como se definiera en Peña $(1991,1998)$, el "arreglo" consiste en la búsqueda autocompositiva de la solución por las propias partes de un conflicto determinado. Las partes sienten que algo no marcha bien, que algo está «malogrado», por tanto que requiere «reparación". En términos sencillos, en esta "reparación" consiste el «arreglo».

A través de la "reparación» las partes en conflicto buscan volver las cosas a su estado anterior, volver a la "armonía» que pudo haber identificado a las partes del pleito, para lo cual también aparece como un elemento sustancial saber comprender y aplicar el ejercicio de sacrificios recíprocos sobre las pretensiones alegadas por las partes. Estos sacrificios se ven condicionados por la homogeneidad $u$ horizontalidad que identifica a las partes. La pretensión alegada por una de las partes se opone a otra pretensión alegada por su similar, tratándose, en consecuencia, de supuestas oposiciones de intereses homogéneos. Si la pretensión fuera alegada por un colectivo frente al particular, ciertamente que tal homogeneidad no existiría.

Pues bien, explicados resumidamente esos elementos que caracterizan el "arreglo", se puede deducir que resultan ser los conflictos intercomunales entre particulares o entre familias los que más se adecuan a tales características. Sin embargo, a ellos se van a sumar también un conflicto de carácter colectivo o comunal, el más complejo, que consiste en el conflicto de linderos territoriales entre comunidades vecinas. En todos ellos podremos notar, siguiendo la concepción de los comuneros, que hay algo «malogrado» que requiere "reparación", algo del que las propias partes pueden hacer sacrificios con tal de alcanzar una solución, lo que se ve condicionado por esa homogeneidad que identifica a las partes en disputa. 
En los típicos conflictos intercomunales de parejas, el «arreglo» se traduce en el acuerdo armonioso de ambas familias, consanguínea o ritual, y en el asentimiento de sus propias autoridades. Así, en un acta registrada en la comunidad de Calahuyo sobre un caso de maltratos entre un comunero de Calahuyo y una comunera de Quencha ${ }^{82}$, podemos apreciar:

«2. El demandado don J.Q.U. reconoce integramente sus faltas y maltratos a su convivienta M.L.V. con domicilio en la parcialidad de Quencha».

3. El demandado ante sus autoridades y familiares, se compromete en lo sucesivo evitar daños corporales y maltratos que pueda ocurrir en estado de ebriedad, como también en estado de reacciones personales.... ${ }^{83}$.

El caso citado puede mostrar los límites de un conflicto familiar y su posible conversión en un conflicto colectivo de interés de la comunidad. Sin embargo, por la naturaleza del matrimonio aimara, puede entenderse que tal conflicto de maltratos, en tanto involucra a la pareja, es de competencia principalmente familiar. En este sentido es que se busca el "arreglo" entre las partes, pero con una característica especial: más que el acuerdo de la pareja en conflicto es el acuerdo entre los familiares de ambos, quienes, con el respaldo de sus autoridades, primero consiguen el arrepentimiento y seguidamente el acuerdo del agresor.

Es interesante destacar cómo los familiares de ambos comuneros que componen la pareja en "pleito" buscan con prioridad suplir las causas del conflicto del maltrato antes del registro del "arreglo". Por ejemplo, se refieren a los "celos" del varón o a la "ociosidad" de la mujer que no responde a los requerimientos del varón para que la pareja salga "adelante". Padre, padrinos y autoridades pueden verse involucrados en largas conversaciones para hacer ver

82 Quencha es una comunidad vecina a Calahuyo.

${ }^{83}$ Calahuyo: "Arreglos sobre maltrato de conviviente de Quencha, en Libro de antecedentes, acta del año 1984, registrado a fojas 27-28. 
que dichos problemas pueden superarse con la intención de buscar la "armonía" de la pareja, que resulta ser la "armonía" de las propias familias.

Sin embargo, puede ocurrir que los maltratos o las disputas en la pareja sean reiterados o hagan difícil, desde una de las partes familiares, aceptar del transgresor un compromiso de evitar maltratos posteriores. En tal caso, el "arreglo" puede significar la separación de la pareja ${ }^{84}$. A partir del registro de tal acuerdo, renunciarán a su situación actual de casados o convivientes, volviéndose a su situación inmediatamente anterior. Para ello, los familiares respectivos ya han preparado el ambiente en sus comunidades para recoger en su nueva condición a la pareja que se desune. La mujer volverá al seno de su familia nuclear, en tanto el varón se quedará en la casa que construyeran para la vida en común o, de no existir ésta, se quedará en el seno de su familia nuclear, que cobijó a la pareja.

Se trate de convivientes o casados, la separación opera igual, como si se tratara de un conflicto intracomunal. Así hayan procreado uno o dos hijos, la pareja, sin prejuicios, puede volver a su situación anterior. Los hijos pueden pasar a ser "adoptados" como hijos por quienes realmente son sus abuelos, para que la propia mujer, en caso de ser joven, tenga menores limitaciones de contraer nuevas nupcias ${ }^{85}$.

Asimismo, opera la posibilidad de partición de los bienes materiales de la pareja que se separa. Lo que significó una especie de 'sociedad de gananciales' será distribuido de acuerdo a la racionalidad de las propias familias. Si tuvieron cebada, habas, papas, quinua, ovinos y algún ganado, dispondrán que determinados bie-

${ }^{84}$ Pueden consultarse al respecto los casos de Titihue: "Acta de separación entre las personas NMM (y) ML de la comunidad de Huancho", en Libro de antecedentes, acta de fecha 11-4-95; "Acta de separación (de comuneros convivientes pertenecientes a Titihue y Chijullani)", en Libro de antecedentes, acta de fecha 13-8-97.

${ }^{85}$ Cabe recordar que, en la concepción de los comuneros, la presencia de nuevos hijos es entendida como fuerza de trabajo disponible para las diversas actividades agropecuarias de la familia nuclear. Ello difiere de otras microrregiones, en las que la mayor escasez del recurso tierra crea limitaciones para extender dicha concepción. 


\section{ANTONIO PEÑA JUMPA}

nes queden en manos del varón y otros pasen a manos de la mujer. El varón puede quedarse con el ganado para asegurar una fuente de ingreso permanente que sirva para mantener viva una pensión en favor de la mujer y de los niños, si los hubiera, siempre que así lo hayan considerado recíprocamente ${ }^{86}$.

En los conflictos de incumplimiento del contrato de "cría" o «engorde» de ganado, puede apreciarse sólo como parte de su solución el "arreglo». La otra parte de la solución consiste en un tipo de "sanción» privada que explicaremos más adelante.

En estos casos, el "arreglo" es un producto del reconocimiento del "error" en el que hubieren incurrido las partes. Cualesquiera de las familias partes del contrato, representadas por el jefe de familia, quien habría celebrado también el contrato, se ven requeridas por el dinamismo de sus relaciones económicas a agotar el conflicto para "no seguir perdiendo el tiempo». Las partes entienden que deben mantener en "armonía» sus relaciones de "socios" para en el futuro poder seguir manteniendo ese mismo tipo de relación. Entonces, las partes harán el sacrificio económico que crean conveniente para dar paso a un acuerdo que responda a sus expectativas.

Si la razón del conflicto consistió en la pérdida de una cría del ganado dado a reproducir, las partes pueden acordar que la siguiente cría de todas maneras pasará al propietario del ganado y aplazaría la tenencia del ganado madre para una tercera cría, que revertirá en favor de quien se vio afectado en la pérdida. $\mathrm{O}$ en el caso de que no se haya alcanzado el "engorde» deseado del ganado, con lo que no se alcanzaría tampoco un buen precio, entonces pueden acordar el aplazamiento en la tenencia del ganado para que, en efecto, se llegue al punto de "engorde» deseado y luego se produzca la venta, o puede acordarse de que, ante la urgencia, se produzca la venta en feria del ganado pero el

${ }^{86} \mathrm{Al}$ respecto, puede consultarse el caso de Titihue: "Acta de diligencia de inventario (de dos jóvenes comuneros separados)", en Libro de antecedentes, acta de fecha 15-4-95. En dicho caso, las autoridades, con las partes familiares, se trasladaron hasta la ciudad de Juliaca, ciudad situada a más de 40 kilómetros de la comunidad, para realizar el inventario y distribución de bienes de lo que fue el patrimonio conyugal. 
porcentaje de ganancia que le correspondía a la parte que debió engordar el ganado disminuya ${ }^{87}$.

Puede notarse una racionalidad económica evidente de parte de los comuneros. Claramente calculan el costo de una cría de ganado o la pérdida que le puede ocasionar que el ganado no se encuentre en su punto de "engorde" para alcanzar un buen precio en las relaciones del mercado de la región.

En estos casos, el carácter autocompositivo siempre está de lado de ambos comuneros. El «arreglo», de ser posible, se materializará con la disposición y sacrificio de parte de sus intereses de ambas partes. En caso contrario, quedará la amarga sensación del comunero más afectado por tener que acudir a un tipo de "sanción» privada, extendida a la parentela del supuesto trasgresor y advertida a la propia parentela del comunero, la de «nunca más entrar en negocios con dicho comunero".

De otra parte, en los casos de los conflictos de linderos sobre parcelas de la comunidad en los que un "yerno" que no vive habitualmente en la comunidad se cree con el mejor derecho, el «arreglo" puede tener dos etapas. Una primera consiste en la llegada a un acuerdo "armonioso", producto de la iniciativa de los propios comuneros del pleito -el comunero vecino y el "yerno»-, sin necesidad de formalizar el acuerdo o llegándolo a formalizar sólo de manera complementaria. Y la segunda, en la que, no alcanzado tal "arreglo armonioso", se pase a las autoridades comunales para que desde éstas se asuma un acuerdo o "arreglo forzado", que puede estar acompañado hasta de multa.

En el «arreglo armonioso» son las propias familias colindantes, esposos o convivientes, quienes mutuamente, por propia iniciativa, se ponen de acuerdo como si se tratase de un conflicto familiar interno. Ambas partes redefinen cuáles son las líneas del korpac para levantarlos con mayor precisión y así volver a las relaciones de 'buenos vecinos' habidos. Frente al «yerno» que no vive habitualmente en la comunidad, recurre su esposa o conviviente como comunera originaria, acompañada de su parentela, también origina-

${ }^{87}$ Entrevistas realizadas en Titihue, Calahuyo, Tiquirini-Totería, marzomayo 1988, mayo 1991, marzo 1992, octubre 1999. 
ria de la comunidad, para alcanzar ese tipo de solución al conflicto ocurrido.

El otro tipo de "arreglo" que solemos diferenciar como "forzado" es cuando el mismo conflicto alcanza un nivel más colectivo y comienza a interesar, además de a la parentela de cada una de las partes, a las demás familias de la comunidad. El «yerno» que no vive habitualmente en la comunidad puede ser apreciado, por sus actos o por error, como un comunero "pleitista», "abusivo", que se quiere aprovechar de los recursos de la comunidad sin tener el derecho de los comuneros originarios. Es la razón por la que son las autoridades comunales las que más directamente asumen el conflicto y fuerzan a que lleguen a un acuerdo entre las partes en pleito.

Sea cualquiera de las dos formas de "arreglo", las partes del conflicto se verán comprometidas a un volver en «armonía» sus relaciones como comuneros vecinos. En adelante quedará resaltado cuáles son los límites de las respectivas parcelas en pleito. Si el «yerno" que vive habitualmente en la comunidad hubo actuado con prepotencia, queriendo usurpar la parcela vecina, se verá sometido a un control estricto que, además del «arreglo» forzado orientado en su desmedro, podría terminar con la aplicación de sanciones graves, como es la expulsión de la comunidad ${ }^{88}$.

Otro tipo de conflicto que termina en esta institución del «arreglo» comunal es el referido al conflicto de colindancia intercomunal, calificado probablemente como el más complejo de las relaciones intercomunales. Como hemos venido afirmando, en tal caso nos encontramos con el conflicto en el que se confrontan dos colectivos, dos conjuntos de comuneros con sus respectivas autoridades. Es decir, son dos partes con idénticas condiciones de negociación, dos partes homogéneas o equivalentes, que muy bien, dada la racionalidad propia de los comuneros, podrían sacrificar partes de sus reclamos para arribar a una solución del conflicto. Por más que la litis se entienda que involucra al colectivo $y$, por tanto, pertenezca a la categoría de conflicto colectivo o comunal, la solución no puede consistir

${ }^{88}$ Ver particularmente el caso de Titihue: "Acta de comparencia (por riña y lesiones propiciadas por 'yernos' de la comunidad)", en Libro de antecedentes, acta de fecha noviembre 1997. 
en la imposición de este colectivo, sino, al tener al frente a otro colectivo similar, la única solución, entienden, es la posibilidad de conversar para llegar a esa solución.

La calidad de lo colectivo se relativiza. No estamos ante el conflicto de una familia o de un grupo de familias frente al colectivo, sino de un colectivo frente a otro colectivo, con iguales derechos y obligaciones y, es más, con iguales condiciones de identidad.

Nuevamente, es el ser colectivo de las dos comunidades en disputa el principio rector que hará posible la solución. En la comprensión de que se trata de dos intereses colectivos concurrentes, ambos con la misma legitimidad de avanzar hacía el "progreso" de sus respectivas comunidades, se produce el sacrificio mutuo para luego arribar al acuerdo o «arreglo».

Tal sacrificio, en estos casos, consiste en la renuncia recíproca sobre parte de los terrenos en disputa o en la comprensión de que parte del terreno que reclaman no les corresponde y pueden renunciar al mismo. Ambas comunidades pueden tener la razón, como también puede ocurrir que tengan una equivocada apreciación de los hechos. Lo cierto es que ambas, por la fuerza de la concepción de su ser colectivo, entienden que su conflicto no puede ser indeterminado, debiendo traducirse en un acuerdo inmediato que, en lo esencial, los haga volver al conjunto de relaciones amistosas que pudieron haber tenido hasta antes del conflicto.

Para mostrar el "arreglo armonioso" al que pueden llegar la comunidades en litis, nos permitimos citar el "Acta de demarcación de linderos de la comunidad de Calahuyo y el sector Lacaya de la comunidad de Huancho" 89 , en la que se puede apreciar el arribo al "arreglo", la señal de "buena voluntad" a través de una tinka $a^{90}$ y la demarcación en sí del terreno en litis:

"En el lugar Quellanoha a los dos dias del mes de marzo de mil novecientos ochentaitres siendo a horas once de la manana reunidas las comunidades de Calahuyo y el sector Lacaya

${ }^{89}$ Calahuyo, Libro de actas I, acta de fecha 2-3-83.

${ }^{90}$ La tinka es una ceremonia ritual practicada formalmente con alcohol $y$ hojas de coca. 
de la comunidad de Huancho con la finalidad de marcar los (linderos) entre ambas comunidades Calahuyo y Lacaya bajo la citación de las autoridades.

"El acto de la marcación tomaron las palabras del señor GLL Presidente del Consejo de Vigilancia de la comunidad de Huancho de sector Lacaya quien invoca el motuo acuerdo entre ambas comunidades y así llegar a un arreglo en esta Demarcación. Luego también en este acto tomó la palabra el presidente de Calahuyo el señor PCL quien agradece a este acuerdo(,) se ahona al Presinte acuerdo de Demarcación de linderos entre ambas comunidades; luego tambien tomaron la palabra los señores FQC y el señor MQU quienes estas personas recomendaron a todos los vecinos de ambas comunidades Calahuyo y Lacaya que en esta demarcación de Linderos haya una Democracia y conjunción y llegar sacar provecho del tiempo y no crear problemas entre los vecinos de ambas comunidades.

"Acto seguido, las autoridades como el Presidente de la comunidad de Calahuyo señor PCL y el señor Teniente gobernador don JCL y como las autoridades del sector Lacaya de la comunidad de Huancho el señor JLL. Presidente del Consejo de Vegelancia de la comunidad de Huancho, se levantó una tinca de costumbre en el lugar de 'Amaru Pata' dirigiendose a la Santa tierra.

"Continua la Demarcación autoridades y vecinos de ambas comunidades (reunidos) el punto de Parteda de la Demarcación de "Itos" comienzo del lugar llamado "Amaru Pata" siguido se indica los nombres de los itos poniendo como un señal Prencepal montones de piedra. Es como sigue: Sevacollo Pata, Tile chijjo, quelluncha huichinea, senaccarra Quellancho Pujo, Cruz salto, muna cuyo perka.

"Primero Muna Cuyo Perka, segundo Munacuyo traj Aja Llaulle Cuyo(.) Primero Llaulle Cuyo, segundo Llaulle pujjo que este punto seguirá un largo Cercado de Piedra hacia arreba, alto Huyo Amata, alto Huyo Perka, alto Huyo Cunca. Oeste Tamponi Pata, Pesac Llufiña, Pesac llufiña Perka, Altarani tres peñas, Jjacha pampose pata, Tauca Taucani Pata. 
"La que contenua la Demarcación de linderos quedando en vías de solución desde lugar Aceroni con la comunidad de Calahuyo y sector Lacaya de la comunidad Huancho. "En esta manera se llevó a cabo la demarcación entre las comunidades de Calahuyo y sector Lacaya de la comunidad de Huancho en una forma armoniosa por unanimidad de todos los vecinos de ambas comunidades» (...).

Agregándose al final:

«NOTA: los señores autoridades de ambas comunidades harán respetar los Itos colocados en los linderos bajo una sanción que la asamblea de cada comunidad lo decederá» ${ }^{91}$.

Luego de las negociaciones a las que pudieron llegar las autoridades de ambas comunidades, con la aprobación de sus respectivas asambleas, ambas partes colectivas se reúnen en el área de conflicto con el fin de sellar el acuerdo. Puede destacarse el llamado de las autoridades y los comuneros de ambas partes por vivir en "armonía", "sacar provecho del tiempo sin crear problemas entre los vecinos de ambas comunidades" y la realización de la tinka como un acto especial que ratifica el acuerdo o "arreglo" arribado. Pero también se incluye en éste el procedimiento de demarcación a través de los hitos y "montones" de piedras sobre los terrenos, que sólo ambas comunidades conocen. Finalmente, ambas comunidades, recíprocamente, hacen el llamado de respetar los hitos bajo sanciones que cada comunidad acordará.

Podemos destacar que es el espíritu autocompositivo de las comunidades, expresado a través de sus autoridades y comuneros "notables", lo que impulsa esta forma armoniosa de solución. No es la fuerza física o la reacción brusca de los comuneros lo que prima, sino la idea de desarrollo o progreso ("no perder el tiempo", "no crear problemas") como parte de la concepción que antes referimos de ser colectivo.

${ }^{91}$ Calahuyo, Ibid, acta del 2-3-83, registrada a fojas 28-31. 
4.2 Las sanciones aplicadas en los conflictos intercomunales

Las «sanciones" en los conflictos intercomunales se presentan como imposiciones establecidas por el conjunto de comuneros o las autoridades comunales contra el trasgresor de otra comunidad, buscando restablecer el orden comunal que se entiende alterado. En forma excepcional, se añade la "sanción privada" para los casos de incumplimiento de contratos de "cría" o "engorde" de ganado, que consiste en una cierta imposición familiar sobre la parte que incumple el contrato.

La aplicación de una sanción intercomunal, por lo general, tiene su fundamento en una relación desigual de las partes y en la calidad del "daño" ocasionado. La desigualdad de las partes se aprecia cuando, de un lado, se presenta el conjunto de comuneros, que aparece como la parte afectada o transgredida, $y$, de otro lado, el interés familiar, que se identifica regularmente con la parte del transgresor. Tal desigualdad tiene su excepción en los casos de incumplimiento de los contratos de "cría" o "engorde" de ganado en que la "sanción privada" opera sobre aparentes relaciones homogéneas. El daño ocasionado se aprecia cuando se trata del daño a una propiedad comunal o una propiedad familiar que produce los efectos del daño comunal al tornarse en "escandaloso" el conflicto, o simplemente cuando se daña o afecta la vida normal de la comunidad, su orden o convivencia colectiva. Bajo tales condiciones, el conjunto de comuneros afectados o transgredidos considera pertinente "poner orden", lo que significa sancionar al transgresor o a la familia transgresora que ha producido el "daño".

Retomando el análisis de los conflictos intercomunales que hemos venido citando, cabe señalar que la sanción, en los términos referidos, se aplica en los casos de incumplimiento de obligaciones comunales o participación del "yerno" de la comunidad en riñas, los casos de robo de ganado u otro tipo de robo y en los casos de insatisfacción o afectación de una de las partes privadas derivadas del incumplimiento de los contratos de "cría" o "engorde" de ganado.

La sanción a los conflictos derivados del incumplimiento de obligaciones comunales de parte del «yerno» o por participa- 
ción en riñas que connotan un daño al interés comunal se subsume dentro de los mecanismos recurridos para los conflictos propiamente intracomunales. Son las propias autoridades o asambleas de la comunidad respectiva las que asumen la resolución del pleito, como indicáramos; lo que significa que serán los propios mecanismos de sanción de estos órganos los que se apliquen.

Para ello, resulta conveniente recordar los elementos principales de la sanción que se tienen en cuenta para resolver estos típicos conflictos colectivos intracomunales. Resultan tres los elementos de la sanción comunal que tienen en cuenta los comuneros: el primero consiste en el acto de volver las cosas a su estado anterior, lo que significa la reparación de los daños materiales ocasionados y, en todo caso, el asumir una "indemnización" por el daño que no fuera materialmente calculable; en segundo lugar destacamos la presencia del castigo o pena, como elemento más importante y variado, que busca llamar la atención justamente del transgresor haciéndole sentir "mal"92; y tercero, de manera complementaria se presenta la amenaza de un castigo más severo, que consiste en advertir al causante de que si reincide en el "delito" o en el hecho que produce el conflicto se le impondrá un castigo que le hará sentir un mayor daño. Estos elementos, justamente, tienen aplicación para casos como el que corresponde al de incumplimiento de las obligaciones comunales de parte del "yerno" no residente.

La aplicación del primer elemento, consistente en volver las cosas a su estado anterior, significa para la comunidad afectada que el «yerno" no residente repare lo que ha ocasionado su ocio, al no haber cumplido con la obligación dispuesta por la asamblea comunal o los daños personales ocasionados en riña. Si se trató del incumplimiento del trabajo comunal, se buscará cumplir con dicho

92 De acuerdo a estudios previos (Peña, 1991, 1998) cabe recordar que los tipos de castigo pueden consistir en: multas, llamadas de atención, trabajo forzoso, destitución del cargo, sometimiento del caso a la autoridades de Huancané, limitación sobre beneficios comunales y expulsión de la comunidad. De todos ellos, destaca la multa como castigo o pena frecuente en los diversos conflictos comunales. 
trabajo, a pesar del destiempo, o se exigirá el pago de una multa acordada, equivalente al jornal dejado de laboral. Si el conflicto consistió en la riña con lesiones entre comuneros, el "yerno" transgresor tendrá que pagar el monto aproximado que significará la curación de las heridas ocasionadas.

El elemento del castigo se aplica adicionalmente al de reparación de los daños ocasionados. Al «yerno» se le llama la atención por su inasistencia a la faena comunal o por la riña ocasionada, y a continuación se le aplica el castigo de la multa. Además del equivalente de la suma por reparar el daño material o personal ocasionado, se establece el pago adicional de una suma que prudencialmente fije la asamblea comunal. En el caso de incumplimiento de la obligación comunal, esta multa normalmente va incluida en el aporte por reparación del daño, no apareciendo notoriamente la diferencia entre ambos elementos.

El tercer elemento de la sanción -la amenaza del castigo más severo- aplicada al "yerno» no residente incumplido es recurrido en caso de permanente irresponsabilidad del "yerno" o en caso de existir desconfianza frente a él de parte de la comunidad. En ambos casos, la amenaza del castigo más severo consistirá en la posibilidad de duplicar la multa impuesta, la limitación de ciertos beneficios comunales $y$, en su caso, la expulsión de la comunidad $^{93}$.

Con ello, como ocurre en los conflictos intracomunales, la comunidad afectada buscará el cambio de actitud del "yerno", su reinserción en las actividades de la comunidad y la mejora o "reforma" de su comportamiento. La referida comunidad tendrá como preocupación "ganar» al "yerno» como «buen comunero", a pesar de no ser originario de ella; en todo caso, exigirá su retiro.

$93 \mathrm{Al}$ respecto, cabe recordar la cita del caso Titihue: "Acta de comparencia (por riña y lesiones propiciadas por 'yernos' de la comunidad)", en Libro de antecedentes, acta de fecha noviembre de 1997. También puede consultarse Titihue: "Confirman y exigen cumplimiento de sanción de comunero por expulsión de dos comunidades", en Libro de antecedentes, acta de fecha 23-5-97. 
De otro lado, los casos de robo de ganado y otros tipos de robos también contemplan, en la aplicación de la sanción correspondiente, los elementos anteriormente señalados. Sólo que, para estos casos, la aplicación de dicha sanción se ve condicionada al esfuerzo de ubicar y capturar a los ladrones ${ }^{94}$.

En el supuesto de que se encuentre a los «ladrones» o autores del "robo", y éstos hayan sido identificados como miembros de una comunidad, como efecto sancionador pueden ocurrir dos alternativas: que las comunidades, tanto del afectado como del comunero "ladrón", coordinen la sanción para éste, luego de identificar su responsabili$\mathrm{dad}^{95}$, o que, tanto los agraviados como las autoridades de las respectivas comunidades, acuerden someter el caso a las «autoridades competentes de la ciudad» (los agentes policiales, principalmente), bajo el criterio de una sanción más severa que se traduzca en cárcel.

En el primer caso, las autoridades comunales asumen jurisdicción y la sanción puede concentrarse en la aplicación de castigos físicos y fuertes multas. Luego de devolver lo robado al comunero afectado (parte de la reparación del daño material), las autoridades de la comunidad donde es miembro el supuesto ladrón, o los familiares de éste, son los encargados de materializar el castigo físico delante de la misma parte familiar que sufriera el robo y de sus autoridades acompañantes. Las "amarradas" o "latigazos" se presentan como la forma de castigo físico más común ${ }^{96}$. En forma alternativa o complementaria a tal castigo físico, corresponde la

${ }^{94}$ Entrevistas a comuneros de Titihue (mayo de 1991, marzo de 1992) y a dirigentes de la Liga Agraria "24 de Junio" de Huancané (Huancané, marzo de 1992). Dos casos conocidos en los que se puede apreciar la recuperación del ganado sustraído y no a sus autores corresponden a los ocurridos en Titihue el año 1992 (caso no registrado), que anteriormente referíamos, y el caso "Robo de ganado en Jasana Chico-Samán", registrado en su Libro de antecedentes, acta de fecha 15-1-98. En estos casos, como puede entenderse, resulta imposible llegar a sancionar a los culpables de los robos.

${ }^{95}$ Es el caso ocurrido en Calahuyo: "Acta de sanción de robo de (seis) ovejas de la comunidad de Huancho, sector Llachojani", en Libro de antecedentes, acta de fecha 22-8-94. También pueden incluirse los casos de Titihue: "Robo de bicicleta y robo de vacas y ovinos" (17-11-94) y "Robo de redes de pescar" (02-3-96), registrados en su Libro de antecedentes.

96 Entrevistas en Titihue, Calahuyo y Tiquirini-Totería, abril-mayo 1988, marzo 1992, octubre 1999. 
ANTONIO PEÑA JUMPA

aplicación de una fuerte multa al ladrón y su familia (parte complementaria de la reparación del daño material). Sobre ello hay una fuerte llamada de atención, el arrepentimiento del ladrón y la amenaza de multas mayores, someter el caso a las autoridades de la ciudad y hasta el "retiro" de su "condición de comunero" en caso de reincidencia (amenaza de pena severa). Frente a ello, el comunero sancionado tiene dos alternativas: corrige su actitud o termina alejándose de la comunidad bajo supuesta migración por trabajo ${ }^{97}$.

En el otro caso en el que las autoridades comunales encabezadas por sus tenientes gobernadores someten al «inculpado» a los agentes policiales más cercanos, exigen de inmediato que tal comunero sea encarcelado. Sólo de esta manera se sienten satisfechos de la posibilidad de un castigo más severo. Entenderán que empieza una tragedia que no olvidará el "mal comunero": la lentitud de la justicia oficial, los gastos judiciales y los gastos en su defensa propiamente. A ello se suma el mayor desprestigio de su honor familiar, no sólo ante la vista de sus comuneros vecinos sino ante los comuneros de la microrregión. Es quizá uno de los castigos que el propio comunero "inculpado", respaldado por su familia, más buscará evitar ${ }^{98}$.

A estas dos situaciones se puede sumar también una tercera posibilidad de sanción, que combina las dos anteriores. Consistiría en que, de un lado, los comuneros tanto de la comunidad afectada como de la comunidad donde es miembro el supuesto ladrón asumen la jurisdicción primaria, aplicándole los castigos que crean convenientes -variando desde la llamada de atención hasta los castigos físicos-, para luego recién someter al «inculpado» o "acusado» ante las «autoridades competentes de la ciudad». Ciertamente que antes se hubo concretado la devolución de lo robado y no se dejará esperar la amenaza de un castigo más severo ${ }^{99}$.

97 El retiro voluntario del comunero sancionado puede encontrar su explicación en el daño del honor de su familia nuclear y de su familia extendida (Entrevista, 1988, 1992 y 1999).

${ }^{98}$ Anotemos que este tipo de castigo siempre se vería precedido por la devolución de la cosa robada y, en su caso, de la amenaza de un castigo más severo, que podría consistir en la expulsión de la propia comunidad.

${ }^{99}$ Puede tenerse en cuenta que esta última posibilidad aparece como la más extrema, ante la reincidencia de las "faltas" o "delitos" propiamente. 


\section{JUSTICIA INTERCOMUNAL EN LAS COMUNIDADES AIMARAS}

Dentro de los mismos conflictos de robo de ganado, también puede ocurrir que el comunero ladrón o los comuneros ladrones no pertenezcan a alguna comunidad de la microrregión o de la región conocida por los comuneros, sino que pertenezcan a pueblos lejanos o sean de las grandes ciudades como Juliaca, Puno o Arequipa ${ }^{100}$. En estos casos, la situación se complica para los comuneros afectados, sobre todo para la búsqueda de estos ladrones. Sin embargo, en el caso de que logren ubicarlos, las sanciones que se aplicarán serán la combinación de los castigos de la propia comunidad con la del sometimiento de dichos ladrones a las respectivas "autoridades competentes de la ciudad» hasta que sean encarcelados ${ }^{101}$.

Por último, un tipo adicional de conflicto en el que es posible destacar la presencia de la sanción como forma de acuerdo o decisión final lo encontramos en los incumplimientos de los contratos de "cría» o «engorde» de ganado. Se trata de la situación en que una de las partes ha quedado totalmente insatisfecha sin la posibilidad de un "arreglo armonioso». En tal situación, el comunero afectado, rehuyendo tanto la intervención de sus autoridades comunales como de las autoridades comunales del otro comunero "contratista", aplica una especie de sanción privada contra el referido «infractor». Considera que ya «nunca más celebrará contratos con ese comunero incumplido", expandiendo tal sanción hasta la parentela cercana de éste.

${ }^{100}$ Las ciudades de Juliaca y Puno pertenecen al mismo departamento surandino de Puno, donde también se encuentra Huancané. Arequipa es la capital de otro departamento, ubicado al noroeste del departamento de Puno, cuyo nombre es Arequipa también. Por su dimensión e historia, Arequipa es considerada la segunda ciudad más importante del Perú, después de Lima.

101 Se conoce para estos casos, sin embargo, de prácticas de otras microregiones, en las que una vez identificados y capturados estos ladrones "extraños" pueden llegar a ser sancionados duramente (castigos físicos) y en algunos casos hasta "ejecutados" (muertos). Ello ocurre particularmente cuando dichos ladrones "extraños" son reincidentes y la policía, fiscalía y juzgados no cumplen la labor de controlarlos (Juliaca, Huancané, octubre 1999, agosto 2000). 
Los efectos de la sanción privada indicada, en realidad, pueden extenderse a toda la comunidad y a comunidades vecinas. Lo que le pudo ocurrir a alguien como algo "malo" es fácil de ser aprehendido y difundido entre los miembros de la misma comunidad. Todos, al final, no querrán recibir al comunero incumplido, si se trata del proveedor de ganado, o no buscarán más al comunero incumplido, si se trata del que incumplió en la "cría» o «engorde» de ganado.

Es, sin duda, una sanción económica, en el sentido de que si el incumplido era el que proveía ganado para «engorde» o para "cría", dado que carecía del suficiente pasto o forrajes, ahora se verá imposibilitado de recurrir a la comunidad cercana donde había encontrado el interés de un comunero o familia con posibilidades de mantener tal ganado. Tendrá que recurrir a comunidades más lejanas, con mayor costo para ello. De otra parte, si el incumplido es quien proporcionaba el forraje o pasto para el «engorde» 0 "cría» del ganado, en adelante se verá privado justamente de tal ganado, debiendo esperar el interés de otra persona que le provea de ganado. En ambos casos, complementariamente, estará presente el desprestigio exterior que brota hacía otras comunidades de parte de tal «incumplido». No será fácil para el comunero incumplido, luego de que la noticia se hubo expandido en las comunidades vecinas, conseguir un buen proveedor de ganado o un buen «criador» o pastor.

Tal sanción privada aparece, en nuestra opinión, como una forma de control social para las propias relaciones privadas en las que puede encontrarse un interés de lucro o ganancia. Dadas las propias relaciones personalizadas de los comuneros, los intercambios económicos deben ajustarse a tal supuesto, por más que, de por medio, exista la posibilidad de ganancia y de crecimiento del comunero que acumule más. Por ello mismo, existe en el conjunto de comuneros el criterio de mirar no con buenos ojos al "sujeto» que, en su ambición, se dedica a acumular esas "ganancias" 102 .

102 Entrevistas en Calahuyo, Titihue y Tiquirini-Totería, en marzo-junio 1988, marzo 1992, octubre 1999. 


\section{LA RACIONALIDAD EN LA EJECUCIÓN DE LOS ACUERDOS O DECISIONES FINALES}

De manera complementaria a la actitud asumida por los comuneros en la resolución de sus conflictos, aparece como necesaria también su participación en la ejecución de los acuerdos o decisiones finales de los mismos. Entienden, como ocurre para los conflictos intracomunales, que deben terminar con el conflicto, borrarlo totalmente de la relación que pudo marcar a las partes en pleito.

Esta participación en la ejecución de los acuerdos o decisiones finales para los conflictos intercomunales podemos diferenciarla también en dos niveles: a nivel de los propios conflictos particulares o privados en los que destacará el «arreglo» como forma de acuerdo o decisión final principal, y a nivel de los conflictos de interés colectivo o comunal, en los que de manera principal la «sanción» se presentará como acuerdo o decisión final ${ }^{103}$.

\subsection{Ejecución de los acuerdos finales para los conflictos intercomunales de carácter familiar o privado}

Dentro de los conflictos intercomunales de carácter familiar, privados o particulares, la ejecución de los acuerdos o el cumplimiento de los términos acordados en el "arreglo» o acuerdo final asumido corresponde a las propias partes intervinientes. Tratándose de cualquier conflicto particular, como el de los conflictos de pareja, el de problemas de linderos con el «yerno» no residente o inclusive en los casos de incumplimiento de contratos sobre "cría" o "engorde» de ganado, es el propio individuo-familia o su familia nuclear acompanada de su parentela la que asume el cumplimiento de lo acordado en términos de búsqueda de extinción del conflicto.

${ }^{103}$ En el presente esquema hay que tener en cuenta la situación particular del conflicto familiar de índole intercomunal que se suscita por el incumplimiento de los contratos de "cría" o "engorde" de ganado, que, a su vez, incluye la sanción privada, y también la situación particular del conflicto colectivo suscitado entre dos comunidades por los límites de colindancia, en los que aparece el acuerdo o "arreglo" entre comunidades como sanción final. 
Frente a ello, la labor de las autoridades comunales aparece simplemente como complementaria. En caso de notar irregularidades, insatisfacciones en la propia ejecución de los acuerdos del que ellos fueron testigos o fueron convocados para su resolución, intervendrán. Pero, por lo demás, esta labor es limitada, pues puede ocurrir que las propias partes modifiquen, ante el mal entendimiento de lo acordado anteriormente, los términos del acta registrada para satisfacer propiamente nuevos intereses recíprocos.

Así, en el caso de los conflictos de pareja, una vez que hayan acordado el cese de los maltratos, la llamada de atención del varón impulsivo o la separación de la pareja de jóvenes casados, serán las familias, tanto del varón como de la mujer, quienes se encargarán de cautelar el fiel cumplimiento de lo acordado. En el caso del cese de los maltratos, por ejemplo, aunque la mujer viva en la comunidad de origen de su esposo o conviviente, los familiares de ella estarán bien informados de la posibilidad de un nuevo maltrato. Con las visitas periódicas que hacen estos familiares -padres y padrinos- a la pareja, o con la visita que efectúa la esposa o conviviente a sus padres o padrinos en su propia comunidad de origen, el control del cese de los maltratos puede ser notorio. Después del acuerdo tenido, el comportamiento de la mujer maltratada cambia; al notar la protección de su familia, a pesar de estar casada o en serviciña, ella se siente con la libertad de acudir ante estos familiares o ante las propias autoridades donde estuviera residiendo con tal de escapar de situaciones difíciles, como puede ser la agresividad permanente del varón.

En caso de que el acuerdo frente al conflicto de la pareja haya consistido en la separación propiamente, la ejecución de dicho acuerdo es asumida de manera más práctica. Después de asumido el acuerdo, y ciertamente después de distribuidos los bienes de la pareja, la mujer vuelve a su comunidad de origen acompañada de sus familiares. Puede volver, inclusive con hijos, como adelantáramos, y con el compromiso de que el padre de éstos le hará llegar siempre una manutención en víveres o en dinero para ellos ${ }^{104}$. Para

104 Entrevistas en Titihue, Calahuyo y Tiquirini-Totería (marzo-mayo 1988, marzo 1992, octubre 1999, agosto 2000). Esta forma de actuar a su vez puede deducirse del caso de Titihue: "Acta de separación de cuerpos (de 
estos casos, las familias de ambas partes y los padrinos en su caso -quienes no pudieron impedir la separación de la joven parejacautelarán el cumplimiento de lo acordado. La mujer principalmente vuelve a su seno familiar como una hija a la que se deberá cuidar, en tanto que el varón vuelve a una cierta libertad que le brinda la preeminencia patrilineal reconocida en la región surandina. Los familiares de ambas partes serán cautelosos de cuidar que la pareja no se vuelva a encontrar; entienden que tal separación fue definitiva y que, en principio, no cabe conciliación alguna. Ambas partes familiares, además, se preocuparán por cuidar el niño o niños nacidos en la unión de la pareja. Pudiera ocurrir que el abuelo paterno decidiera cuidar al niño y lo asimile como un hijo suyo propiamente, aunque es más común que el abuelo materno se encargue de ello ${ }^{105}$. En cualquier caso, la garantía del cuidado del niño, su manutención principalmente, es asumida por ambas partes.

De otro lado, en los conflictos derivados del incumplimiento del contrato de cría o engorde de ganado, sea cual fuere su solución, el ámbito de ejecución del acuerdo es de competencia también familiar. De mediar un "arreglo armonioso», en el que ambas partes intervinieron, será en el mismo momento, con las mismas partes, en que se ejecuten los términos de tal acuerdo. Si se acordó la entrega de la segunda cría en favor de quien diera el ganado, al nacimiento de ésta y al paso del tiempo necesario para que tal cría adquiera su autonomía, se entiende que volverá a manos del comunero proveedor el ganado madre; esto aunque la primera cría se hubiese perdido al momento de su nacimiento en perjuicio de la otra parte. En caso de que los términos del «arreglo» hayan consistido en la disminución de las ganancias para una de las partes, entonces, al momento de la distribución de tal ganancia,

convivientes de Titihue y Chijullani)", en Libro de antecedentes, acta de fecha 138-97. En este caso es la mujer la que decide la separación, señalándo: "El (conviviente) NM no quiere separarse de su esposa y también (sus) familiares no están (de) acuerdo con la separación. Y así también posterior no habrá ningún reclamo de su gestión o embarazo de dos meses: así declara al momento de separación la señora PChM (la convivienta)".

${ }^{105}$ Entrevistas diversas que se confirman en Calahuyo, Titihue y TiquriniTotería (marzo-junio 1988, marzo 1992, octubre 1999, agosto 2000). 
inmediatamente después de la venta en feria del ganado, se producirá la ejecución de tal acuerdo. Estos acuerdos son ejecutados evaluando el carácter o sítuación de las relaciones económicas del momento.

De no mediar «arreglo» y el conflicto deviniera en la insatisfacción total de una de las partes, quien decidiera aplicar la sanción privada de "no celebrar contrato nuevamente con el comunero incumplido", los términos de tal determinación serán de ejecución también del ámbito familiar. Pero, como se ha explicado, esta reacción es unilateral, de parte del ámbito familiar que se siente afectado, siendo la familia de la parte «incumplida» receptora o la parte pasiva de tal determinación. Sin embargo, tal reacción familiar puede tener efectos colectivos que van más allá de la parentela y de las comunidades de las partes en conflicto. El individuo-familia afectado, más allá de su ámbito familiar y haciendo uso de las relaciones personalizadas entre comuneros, hará presente su insatisfacción de manera pública en los k'atos semanales o en las fiestas periódicas intercomunales, para que el resto de comuneros tenga en cuenta "la falta de palabra" del comunero "incumplido". Esta forma de cumplimiento de la sanción privada no requiere nuevamente de la intervención de las autoridades de los comuneros en pleito, salvo que la disputa adquiera la forma de "riña" o de agresiones verbales.

En los conflictos de linderos, por último, en que una de las partes corresponde al "yerno" que no vive habitualmente en la comunidad donde se encuentran las parcelas en discusión, la ejecución del acuerdo corresponde también al propio ámbito familiar, incluido el del propio "yerno». En caso de mediar el «arreglo armonioso" como solución final al conflicto, ambas partes, por iniciativa propia, acompañados de sus esposas o convivientes, como de los familiares que hubieron intervenido, ejecutan los términos del acuerdo. Levantarán nuevos korpacs que definan los linderos de las parcelas en discusión y volverán a la armonía como buenos vecinos comuneros. Para ello, las parentelas de ambas partes y, en su caso, las autoridades de la comunidad en la que se ubican las parcelas cuyos linderos se discuten, serán los testigos del acuerdo adoptado. Una tinka de alcohol y hojas de coca complementan 
todo ello, con lo que se sella el conflicto y se desean nuevos augurios para ambas partes ${ }^{106}$.

Frente al mismo tipo de conflicto de linderos, en caso de no mediar el "arreglo armonioso» y más bien se recurra ante las autoridades de la comunidad en la que se encuentran las parcelas en conflicto, se asumirá como consecuencia el tratamiento de un "arreglo forzado": a la intervención de las propias partes y de sus familiares presentes se suma la intervención de las referidas autoridades. Presidente y teniente gobernador, o teniente gobernador del sector para comunidades, como Titihue o Tiquirini-Totería, se convertirán en los intermediarios de la resolución así como de la ejecución de la solución adoptada. Con la presencia de estas autoridades se levantará el nuevo korpac o se ratificará el que fue puesto en duda. La parentela de las partes familiares, como éstas propiamente, estarán al lado de tal actuación de las autoridades, aunque siempre serán las primeras las que más cautelarán el cumplimiento de la solución acordada ${ }^{107}$.

Después de la ejecución del "arreglo» adoptado, cada parte volverá a su faena familiar, a su labor de barbecho o de remoción de sus parcelas, teniendo muy en cuenta las recomendaciones del acuerdo. El korpac o límite de cada parcela ha sido precisado o ratificado, estando advertidas cada parte de ello, incluidos sus familiares, no quedando sino el respeto mutuo desde dichas partes.

\subsection{Ejecución de los acuerdos finales para los conflictos intercomunales de carácter colectivo o comunal}

En la solución del conflicto comunal o colectivo que involucra a dos comunidades, será el colectivo de ambas, en principio, el que se sienta comprometido en su ejecución. A través de sus autoridades o a través de su asamblea comunal, la comunidad afectada o ambas comunidades pondrán en cumplimiento los términos de la «sanción» o acuerdo adoptado.

${ }^{106}$ Entrevistas a comuneros en Calahuyo, Titihue y Tiquirini-Totería (Entrevistas 1988, 1992, 1999, 2000).

107 Entrevista a comuneros de Calahuyo, Titihue y Tiquirini-Totería, 1988,1992, 199, 2000. 
Nuevamente cabe destacar que el daño ocasionado es contra el colectivo, contra el conjunto de comuneros, por tanto es este conjunto el que se siente comprometido en concluir definitivamente el conflicto.

Estamos ante la racionalidad de la defensa del ser colectivo de la comunidad y, así se encuentre frente a dos intereses iguales dos intereses colectivos en conflicto-, con mayor razón sus miembros participarán en la resolución.

Así, en el caso de robo de ganado en que se logra detener al supuesto ladrón, identificado como miembro de una determinada comunidad, las autoridades comunales y el conjunto de comuneros de ambas comunidades son los que, luego de asumir el acuerdo sobre el conflicto, se encargan de la ejecución de los términos de la "sanción". Si se hubo acordado remitirlo ante las "autoridades competentes de la ciudad", las referidas autoridades comunales, acompañadas de los comuneros que integran su comisión, son quienes llevan al detenido y entregan mediante acta al comunero «inculpado» ${ }^{108}$. En caso de que se haya acordado la aplicación de determinados castigos al comunero «inculpado», los referidos comuneros -incluido los familiares del transgresor- serán siempre los llamados a materializar tal determinación.

Al igual como fue posible en conjunto atrapar al ladrón, en conjunto los comuneros acuden a sancionar al mismo comunero «irresponsable». Se nota la preocupación del colectivo por limpiar de estas "lacras»" 109 sus respectivas comunidades, aunque, como indicáramos, es raro el predominio de éstas dentro de la microrregión.

En el caso de que el supuesto "ladrón" sea de origen de un lugar lejano, o provenga de las ciudades, la ejecución del acuerdo también será colectivo. Se le aplicará en conjunto -por la comisión nombrada o por el colectivo de la comunidad afectada en generalel castigo acordado y, en conjunto también, se le remitirá a «las autoridades competentes de la ciudad».

${ }^{108}$ Entrevistas en la comunidad de Titihue y a dirigentes de la Liga Agraria "24 de Junio" de Huancané (mayo de 1988 y marzo de 1992).

109 Término común usado por los propios comuneros cuando se refieren a los ladrones de ganado. 


\section{JUSTICIA INTERCOMUNAL EN LAS COMUNIDADES AIMARAS}

De otro lado, en la ejecución de los acuerdos frente al incumplimiento de obligaciones comunales o las riñas propiciadas por el «yerno» de la comunidad, la labor es desempeñada por el colectivo, el cual aplica la sanción, destacándose la actuación de las propias autoridades comunales. Se aplica la misma racionalidad que para la forma de ejecución de los acuerdos sobre conflictos intracomunales de carácter colectivo: el conjunto de comuneros de la comunidad afectada tendrá una atención distinta frente al «yerno» incumplido hasta que se integre a las obligaciones normales en la comunidad, cumpla con las sanciones impuestas o asuma la "reforma" de su conducta.

Los propios familiares de la esposa o conviviente del "yerno", particularmente cuando no vive habitualmente en la comunidad, tendrán un nivel de influencia para que tales hechos de incumplimiento no se repitan. Le «llamarán la atención» y tendrá que someterse a ésta si es que quisiera contar en el futuro con la protección que suele brindar la familia extendida para estos casos. Le exigirán el cumplimiento de la sanción impuesta por la comunidad ${ }^{110}$.

El mismo «yerno" y esposa o conviviente tendrán una apreciación distinta sobre sus obligaciones después de aplicada la sanción. Entenderán que, aunque no vivan habitualmente en la comunidad, el hecho de que estén usufructuando una de las parcelas obliga a comportarse como si en efecto estuvieren viviendo habitualmente.

Por último, en la ejecución de los acuerdos sobre los conflictos de colindancias entre comunidades, esta labor siempre corresponde a ambos colectivos. La ejecución del acuerdo está precedida por un acto solemne consistente en la celebración de una tinka y el subsiguiente levantamiento de los «hitos» en el terreno en conflicto. Los comuneros de ambas comunidades en pleito, luego de haber arribado a un acuerdo, habiendo cedido ambos lados, y encabezados siempre por sus autoridades, acuden a la zona en conflicto para establecer los límites que han acordado. En el caso de estar ésta en la parte del cerro, la que corresponde a los pastos comunales, al día siguiente desde muy temprano se reunirán para el levantamiento de los respectivos «hitos». Todos serán testigos del acto, ratificados por la formalización de las actas que se registran.

${ }^{110}$ Entrevistas en Calahuyo, Titihue y Tiquirini-Totería (ibidem). 
Los «hitos» consisten en bloques de piedra de un metro y medio de altura aproximadamente, levantados cada cierta distancia y sirven para determinar las fronteras de los territorios comunales. Los comuneros comprenden que deben respetar los «hitos» de las comunidades vecinas y no deben sobrepasarse, para evitar los "tropiezos" de la comunidad. Por ello, luego de haber terminado un conflicto sobre los límites del territorio de su comunidad, se sienten comprometidos a participar en su levantamiento o en la confirmación de los ya existentes, si es que se reconoció el mejor derecho de una de las comunidades en "pleito".

Un riachuelo, una quebrada, una carretera, etc., suelen ser utilizados como fronteras naturales que no requieren de «hitos». Sin embargo, para mayor seguridad, los comuneros, en la ejecución de sus acuerdos, recurren necesariamente al levantamiento de esos bloques de piedras, sembríos de plantas o árboles complementariamente. De esta forma es como los "hitos» se constituyen en instrumentos fundamentales que identifican la extensión de la comunidad, derivando de ello que permanezcan mientras dure la existencia de ésta y que sea obligación de los propios comuneros trasmitir a sus hijos el conocimiento sobre tales límites.

Después de asumido el acuerdo y precisados los respectivos «hitos», los propios comuneros aparecen como los agentes complementarios para el cuidado de tales fronteras. Puede notarse su comportamiento especial en los cerros, donde el pasto es común para las comunidades fronterizas. Si un comunero notara que los ovinos de otro comunero de la comunidad vecina está sobrepasando los «hitos», usurpando parte de los pastos comunales, llamará la atención al pastor vecino. En caso tal usurpación se convierta en permanente, nuevamente se desprenderá el conflicto, siendo necesario, entonces, un acuerdo más determinante ${ }^{111}$. Sin embargo, cabe destacar que, una vez conseguido el acuerdo y fijados los hitos, el respeto mutuo no se dejará esperar, y tal vez la nueva usurpación pue-

${ }^{111}$ Es el caso de los acuerdos definitivos que posteriormente se llegaron a celebrar en Calahuyo con las comunidades de Pampa Amaru y Antacahua. En tales casos, puede apreciarse que quedó pendiente la fijación de determinados hitos, y que la duda sobre algunos condujo a una mayor precisión de los mismos. 
da provenir de una parte privada o familiar, cuyo interés particular transgresor será sancionado internamente por su comunidad.

De esta manera es como, a partir de la propia iniciativa de los colectivos, se va concluyendo con el conflicto. No basta sólo el acuerdo, sino la participación directa o a través de sus autoridades de ambos colectivos en su proceso de ejecución. En el respeto y cumplimiento de los límites fijados, en la preocupación y cuidado permanente de parte de los propios comuneros reside la racionalidad de tal labor de ejecución.

\section{CONCLUSIONES}

Ante la pregunta sobre cómo las comunidades aimaras del Sur Andino resuelven sus conflictos externos o intercomunales, puede afirmarse que lo hacen a través de una variedad de sistemas de resolución entre los que se confunden la identificación de particulares tipos de conflictos intercomunales, varios órganos y procedimientos de resolución, diferentes tipos de acuerdos y decisiones finales $y$ varias formas de ejecución de éstas.

Entre los particulares tipos de conflicto intercomunal ha sido posible distinguir conflictos intercomunales de carácter privado, particular o familiar, entre los que destacan conflictos de pareja, casos de incumplimiento de contratos y conflictos de linderos en los que una de las partes es "yerno" de la comunidad; así como conflictos intercomunales de carácter colectivo o comunal, entre los que destacan los casos de robo de ganado, conflictos de colindancia entre comunidades y casos de incumplimiento de obligaciones por los "yernos" de la comunidad.

Frente a ambos tipos de conflicto intercomunal se ponen en operación los propios órganos, procedimientos y acuerdos o sanciones explicados para los conflictos intracomunales, aunque con particulares variaciones. Los conflictos intercomunales familiares convocarán a los órganos de resolución familiar y a las autoridades de las comunidades a la que pertenecen la pareja en pleito, las partes del contrato o el "yerno" de la comunidad, quienes actuarán con flexibilidad, sencillez y celeridad, arribando a "arreglos" o acuerdos sobre los mismos. Los conflictos intercomunales colectivos o fami- 
liares convocarán generalmente a los órganos comunales y los procedimientos de las respectivas comunidades en pleito, para luego llegar a aplicar la sanción al abigeo o al "yerno" en falta, en el supuesto de que sean vecinos de una de las comunidades, así como para llegar a una acuerdo sobre la colindancia de sus territorios.

A su vez, a la puesta en operación de los elementos precedentes en los conflictos intercomunales también se suma la racionalidad de los dos principios fundamentales que, trascendiendo el ámbito de cada comunidad, tienen aplicación: el honor familiar y el ser colectivo. En razón de estos principios, los conflictos de los comuneros pueden llegar a un acuerdo o decisión final y a su cumplimiento.

Ello configura un gran grupo de sistemas de resolución de conflictos referidos a la variedad de conflictos externos o intercomunales de las comunidades aimaras de estudio. Dicho grupo complementa el principal grupo de sistemas de resolución de las comunidades de estudio relacionadas con sus conflictos internos o intercomunales y un tercer grupo de sistemas de resolución referido a la variedad de conflictos internos, externos y gremiales sometidos ante la entidad gremial, la Liga Agraria "24 de Junio" de Huancané ${ }^{112}$. En conjunto, estos tres grupos de sistemas de resolución son los que nos permiten afirmar la existencia de un Poder Judicial aimara en el Sur Andino. Los sistemas de resolución de conflictos intercomunales son una parte importante de este gran poder.

112 Para un mayor detalle de estos tres grupos de sistemas de resolución, véase Peña (2001). 


\section{Bibliografía}

COMUNIDAD DE CALAHUYO

(1973-1999) Libros de actas y Libro de antecedentes, documentos de la comunidad no publicados.

Comunidad DE TITIHUE

(1977-1992) Libros de actas y Libro de antecedentes, documentos de la comunidad no publicados.

COMUNIDAD DE TIQUIRINI-TOTERÍA

(1975-1992) Libros de actas y Libro de antecedentes, documentos de la comunidad no publicados.

CorPoración de Desarrollo de Puno

1983 "Micro región de Huancané", Puno, Corde, documento de trabajo.

LigA AGRARIA "24 de Junio" de Huancané

1975-1999 Libro de actas y actas sueltas, documentos del gremio no publicados.

Peña JUMPA, Antonio

1991 Justicia comunal en las comunidades aymaras del Sur Andino. El caso de Calahuyo (Tesis de Bachiller en Derecho), PUCP, Lima. 
ANTONIO PEÑA JUMPA

1998 Justicia comunal en los Andes del Perú. El caso de Calahuyo, PUCP, Lima.

2001 Poder Judicial comunal aimara en el Sur Andino: Calahuyo, Titihue, Tiquirini-Totería y Liga Agraria de Huancane (tesis de maestría en antropología), PUCP, Lima. 